and social, dangers facing the planet Earth and especially its Biosphere.

3) To emphasize the ethical obligation of the present generation to overcome those current malpractices of resource utilization and those widespread circumstances of intolerable human disparity and overpopulation which lie at the root of environmental unsustainability.

4) To establish whatever programmes are necessary within your university to generate the capability and the capacity necessary to develop appropriate environmental technologies and practices as well as to diminish environmental illiteracy and enhance ethical awareness on the part of staff, students, and the public at large.

5) To cooperate with one another and with all segments of society in the pursuit of practical, effective revision and reversals of those current practices which contribute to environmental degradation, to SouthNorth and other disparities, and to intergenerational inequity.

6) To employ all channels open to the university to communicate these undertakings to UNCED, to governments, and to the public at large.

Howard C. Clark, President

$\&$

MARILYN MACDONALD

Public Relations Office

Dalhousie University

Halifax

Nova Scotia B3H $3 J 5$

Canada.

\title{
SCOPE Sustainable Biosphere Project: A Summary
}

\section{The Imperative}

Throughout the world there has been an increasing awareness that environmental problems resulting from human activities threaten the future of this planet and especially its Biosphere.* The deteriorating state of our global environment, and the ever-increasing demands for resources by the growing human populations, mean that current attempts to prescribe rational approaches for sustaining The Biosphere* are simply inadequate. New approaches must be developed and implemented.

\section{The Challenge}

The SCOPE Sustainable Biosphere project is a new and bold approach to identify the most important knowledge that is necessary for so managing The Biosphere that it will be capable of supporting the next and future generations. In so doing, the Sustainable Biosphere project recognizes the striking dichotomy between the industrialized and the lessdeveloped countries in terms of their population and economic dynamics and the consequences of these asymmetries in resource use and misuse. Moreover, the Sustainable Biosphere project recognizes that time will be required to implement a strategy for sustaining The Biosphere and that the latter itself is not static but will be simultaneously changing in many ways.

\section{The Topics to be Considered}

Not even this innovative SCOPE project can consider all the issues that will need to be addressed; the list of the world's environmental problems is simply too long. Therefore, the SCOPE project is based on two fundamental guidelines for defining the most powerful approach:

A. The issues to be considered in the project will be based on three categories of environmental research priorities; and

B. These research priorities include human social and cultural dimensions as well as physical ones.

The three categories of research priorities emanating from an earlier report are as follows:

\footnotetext{
* With apologies to the SCOPE Secretariat, we are following our long-time custom of capitalizating these initials for dignified emphasis of what matters most. - Ed.
}

1) Diversity and Sustainability:

a) Ecosystem responses to disturbance

b) Consequences of simplification of ecosystems

c) Ways of maintaining diverse ecological systems

2) Sustaining a Changing Biosphere:

a) Evaluating the status of The Biosphere

b) Measuring responses and feedbacks of biotic systems to change

c) Synthesis of information and modelling processes that can be used to prescribe a sustainable Biosphere

3) Human Dimensions of Sustainability:

a) Human populations and renewable resources

b) Relationships between human values and beliefs and the use of natural resources

c) Relationships between environmental conditions and human cultural styles.

Although the details and emphases on these topics will be modified as the project develops, these are the main topics that will receive consideration in the project.

\section{Multidisciplinary Project}

The second fundamental guideline recognizes that these issues all have human social and cultural as well as environmental dimensions. Once again, no project can consider every dimension of every problem. Therefore, the SCOPE project will focus on environmental components but will include experts in economics and other social studies to ensure that these latter aspects are considered in each of the above topics. Involvement of these disciplines will be integral throughout the entire project, including membership of the Scientific Advisory Committee.

\section{Relation to Other Projects}

It is clear that although the focus of this project is primarily on the defined environmental issues, it is really a multidisciplinary effort embracing a wide variety of scientific and other disciplines making it necessary to treat the topics in such a way that there is a reasonable expectation of eventually designing and managing a sustainable Biosphere. Indeed, much of the inadequacy of some other current efforts is just the flaw that disciplines 
are excluded and not brought to bear on these challenges. The Sustainable Biosphere project will remain cognizant of all the other current projects that are aimed at various pieces of the sustainable Biosphere imperative. Indeed, the Sustainable Biosphere project will learn from the experience of these projects, and will share results widely among related studies throughout the world.

\section{Products of the Project}

This SCOPE project is designed:

a) to describe the state of knowledge throughout the world about each of the above environmental issues, and

b) to propose a research agenda that will address the highest-priority issues and questions.

These are global issues found throughout the world in both industrialized and less-developed countries. In fact, many of the issues involve interactions between one or more countries with similar or disparate resources. Therefore, the project will be organized on a world-wide basis, but will accommodate differences among the various regions and countries of the globe.

\section{Process to be Used in Conducting the Project}

The actual process of the project will involve workshops in, probably, seven regions of the world that encompass the global variability in cultural/resource/economic interactions. Such a plan will be feasible in the three years of the project. Each workshop will consider the environmental topics enumerated above, but the treatment of these topics will depend upon the characteristics of the region itself. For example, in some parts of the world simplification of ecosystems and even wider ecocomplexes may be a predominant issue, whereas the relationships between cultural values and natural resource utilization may predominate elsewhere.

The regionally-differentiated issues are controlled by combinations of environmental and social characteristics. As an illustration, in some parts of the tropics nutrient turnover rates are relatively rapid, thus determining the allowable long-term farming strategies. Superimposed on this pattern of environmental variability are such social / cultural patterns as individual and communal land-tenure systems. Each regional workshop will be planned to recognize these important patterns. Regardless of these varying emphases, all the workshops will have the charge of synthesizing the relevant state of knowledge on the topics and then proposing a research agenda addressing the highest-priority issues and problems.

\section{Cumulative Database}

As the workshop series proceeds, there will be an everincreasing database of knowledge, data, and recommendations. In this way, the SCOPE project is designed to capture this incremental knowledge and thus share both the similarities and dissimilarities that will have become part of the individual regional workshops. The final synthesis volume should be of unprecedented richness, drawing on the regional workshops to describe the worldwide status of knowledge about sustaining The Biosphere, and putting forth the highest-priority research recommendations both for each region and for the Earth as a whole.

\section{The Challenge Revisited}

This is an ambitious project that is perhaps as complex as any ever attempted by SCOPE. It focuses on defined yet complicated environmental issues, draws simultaneously on the expertise of many disciplines, and is worldwide although accommodating differences among regions of the globe. It is only with this aggressive and bold approach that we can have any real chance of moving beyond the current state of affairs and eventually being able to prescribe a recipe for sustaining The Biosphere for the next and subsequent generations.*

\section{SCOPE SECRETARIAT \\ 51 Boulevard de Montmorency 75016 Paris \\ France.}

* Here should be borne in mind for correlation the International Sustainable Biosphere Initiative of the International Association of Ecology (INTECOL) - see 'A Sustainable Biosphere: The Global Imperative', Ecology International, 1991: 20 Special issue, pp. 1-14, and, regarding 'Human-caused Soil-ecological Changes and Their Effect on The Biosphere', the incipient project on which a background statement is published on page 197 of the preceding volume of Environmental Conservation. - Ed.

\section{Recommended Policies for Sustainability of European Forest Resources}

\section{Introduction}

Europe's forest industries and forest resources are under pressure as never before. Prominent factors include economic recession (decreased demand and lower prices), structural changes in the industry (increased recycling), and damage to forests caused by air pollutants - particularly airborne acids. In the coming decades, changes in climate caused by global warming are expected to add to these pressures. Such circumstances call for a fundamental shift in thinking about the management of Europe's forests and forest industries. New approaches and policies should be based on the principle of sustainable development, defined by the Brundtland Commission as 'development that meets the needs of the present without compromising the ability of future generations to meet their own needs.'

Most European countries have formally accepted the concept of sustainable development, so the problem is to translate this concept into operational policies concerning forest resources. A major impediment to sustainable development of forest resources lies in the application of traditional economic theory to natural resources. Neoclassical economics has been applied successfully to a wide range of problems, but its application to natural resources reveals fundamental inadequacies.

Conventional valuation techniques, based on the concept of efficiency, stress the welfare of current generations, while discounting the costs to future generations. This short-term approach is inimical to the concept of sustainability, which is concerned with equity and the future. Current policy debates about the future of forest resources in Europe are based principally on the criterion of economic efficiency, not sustainability. Such a discussion obscures the question of sustainability and distorts forest policy. 